\title{
Iron Sound Velocities in Shock Wave Experiments
}

\author{
J.H. Nguyen \\ N.C. Holmes \\ This paper was prepared for submittal to the \\ American Physical Society Shock Wave Conference \\ Snowbird, UT \\ June 28-July 2, 1999
}

August 20, 1999

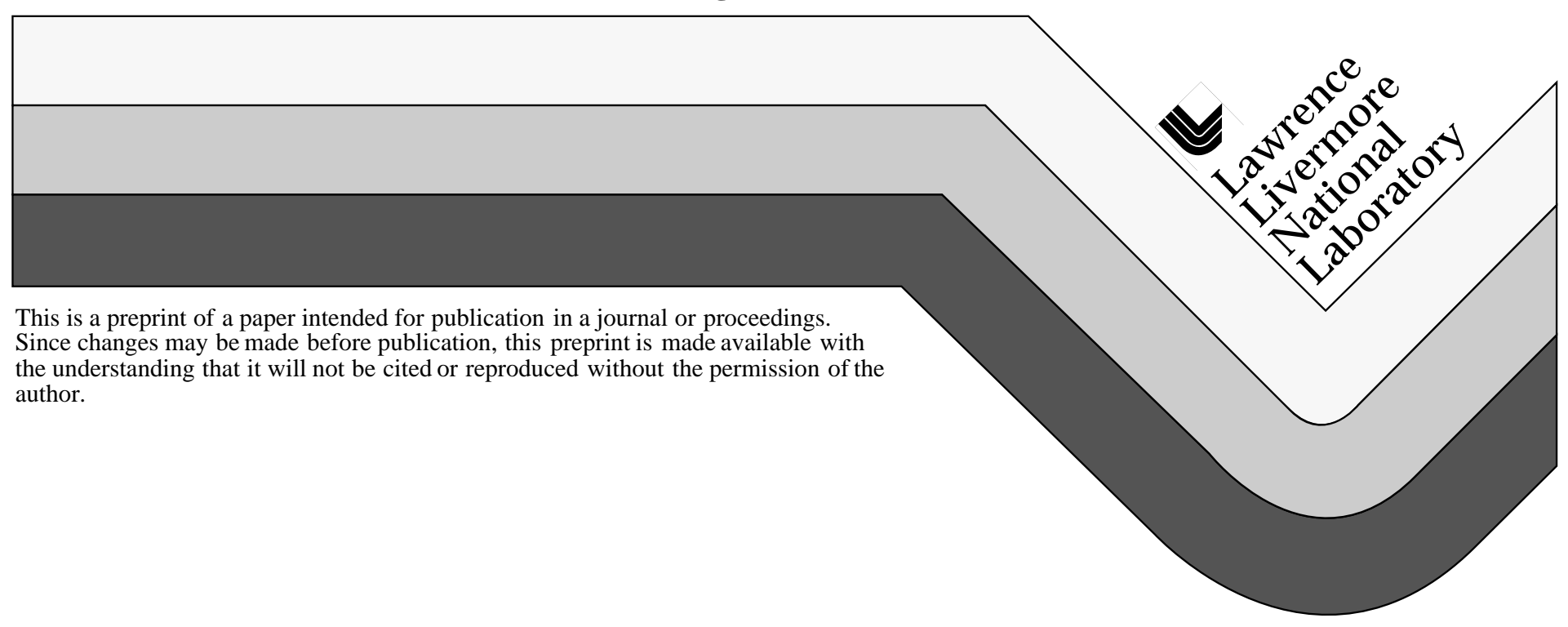




\section{DISCLAIMER}

This document was prepared as an account of work sponsored by an agency of the United States Government. Neither the United States Government nor the University of California nor any of their employees, makes any warranty, express or implied, or assumes any legal liability or responsibility for the accuracy, completeness, or usefulness of any information, apparatus, product, or process

disclosed, or represents that its use would not infringe privately owned rights. Reference herein to any specific commercial product, process, or service by trade name, trademark, manufacturer, or otherwise, does not necessarily constitute or imply its endorsement, recommendation, or favoring by the United States Government or the University of California. The views and opinions of authors expressed herein do not necessarily state or reflect those of the United States Government or the University of California, and shall not be used for advertising or product endorsement purposes. 


\title{
IRON SOUND VELOCITIES IN SHOCK WAVE EXPERIMENTS
}

\author{
Jeffrey H. Nguyen and Neil C. Holmes \\ Physics Directorate, H-Division \\ Lawrence Livermore National Laboratory \\ Livermore, CA 94551
}

\begin{abstract}
We have performed a series of sound velocity measurements in iron at earth's core pressures. Experiments were carried out at shock pressures as high as $400 \mathrm{GPa}$, with particular emphasis on the pressure range between $175 \mathrm{GPa}$ and $275 \mathrm{GPa}$. The measured sound velocities of iron at elevated pressures exhibit a single discontinuity near $250 \mathrm{GPa}$, corresponding to the vanishing of shear strength as the iron melts. A second discontinuity reported by Brown and McQueen in their previous iron sound velocity studies was not observed in our study. Our results are consistent with their data otherwise. Experimental details and error propagation techniques essential to determining the melting point will also be discussed.
\end{abstract}

\section{INTRODUCTION}

Earth's mostly iron core, being at extreme temperatures and pressures, is the primary driving force behind all processes from the inner core to the mantle. At the solid inner core - liquid outer core boundary (IOB), pressure is known to be about 330 GPa. To determine melting temperature, $\mathrm{T}_{\mathrm{m}}(330)$, at the IOB, one needs an accurate iron phase diagram and in particular the iron melting line. Crystallographic structure of pure iron at IOB conditions must also be known to deduce the effect of impurities on $\mathrm{T}_{\mathrm{m}}(330)$. Over the past twenty years or more, there have been many experimental and theoretical efforts to determine the melting line as well as the high pressure-high temperature phases of iron.[1-13] Such a phase diagram has long been sought after as a means to understanding the dynamics deep inside the Earth. These efforts have yet to produce an agreed-upon phase diagram for iron. Inconsistencies include the position of the melting line as well as the existence of high pressure phases.

In the low and intermediate pressure range $(<200$ GPa), diamond anvil cell (DAC) experiments have reported inconsistent temperatures for iron melt line.[2-8] Differing melting criteria and experimental techniques may have contributed to these apparent disparities. Reported melting temperatures at the IOB are as high as $7600 \pm 500$ $\mathrm{K}$ [2] and at low as $4850 \pm 200 \mathrm{~K}$ [3]. Recent improvements in experimental techniques such as double-sided laser heating coupled with synchrotron $\mathrm{x}$-ray diffraction have narrowed the uncertainty of the melt line.[6] The differences are still significant enough to warrant further examination of the iron phase diagram. Moreover, existence of a high pressure - high temperature phase, namely the $\beta$ phase, is still being debated.[4, 6, 8]

At the high pressure range not yet reached by these diamond anvil cell experiments, sound velocity measurements by Brown and McQueen set the upper anchor point for the melt line.[1] In that work, Brown and McQueen reported a solid-solid phase transition at $200 \mathrm{GPa}$ and solid-liquid phase transition at $243 \mathrm{GPa}$. Both of these values are on the iron Hugoniot. The reported solid-solid phase transition suggests the existence of another high pressure - high temperature phase other than the $\varepsilon$ hcp phase. In short, their results have played a very important role in shaping the iron phase diagram debate. Given the importance of such work, it is important that their results be corroborated. We have carried out sound velocity measurements of 
iron up to $400 \mathrm{GPa}$ to re-examine the phase transitions observed by Brown and McQueen.[1] We concentrated our study in the region between $175 \mathrm{GPa}$ and $275 \mathrm{GPa}$ to better quantify these reported phase transitions.

Melting determination from sound velocity measurements is based on the vanishing of shear strength in the liquid phase. In the solid phase, the longitudinal sound velocity is a function both of the bulk and shear moduli; whereas it is just a function of the bulk modulus in the liquid phase. Therefore, as the Hugoniot crosses the melting line, a single discontinuous drop in the sound velocity is expected. Such discontinuities are observed in other metals as in Aluminum, Molybdenum, and Tantalum.[14-15]

\section{EXPERIMENTS AND ANALYSIS}

Using a two-stage gas gun, we measured sound velocities of iron up to shock pressures of $400 \mathrm{GPa}$. To generate such pressures, projectiles were accelerated to velocities as high as $8 \mathrm{~km} / \mathrm{s}$. Two different batches of iron were used in these experiments. The first batch has an initial density of $7.868 \mathrm{~g} / \mathrm{cm}^{3}$. It has a purity of $99.63 \%$; the rest

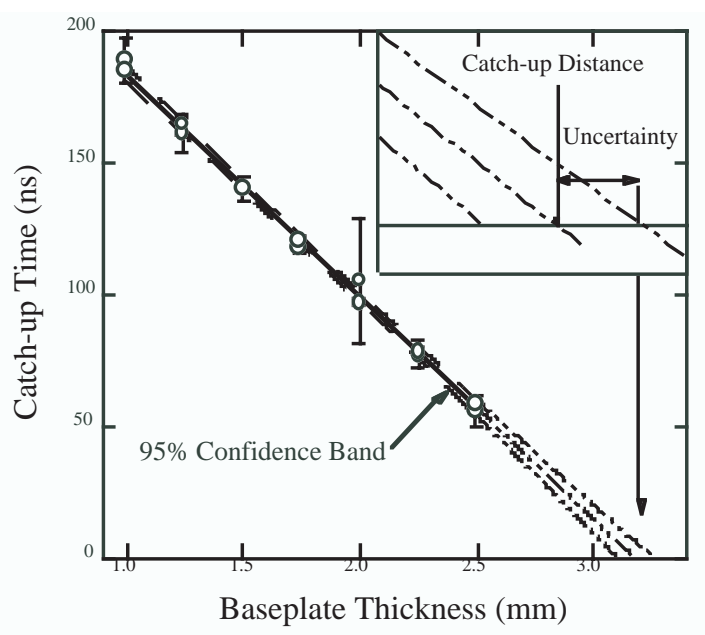

Figure 1. Catch-up time is plotted versus baseplate thickness. Extrapolation to zero catch-up time yields the minimal baseplate thickness, catch-up distance, necessary for the rarefaction wave to catch up to the shock wave while both are still the iron. Catchup distance uncertainty is determined from extrapolation of $95 \%$ confidence bands as shown on the inset. are made up of C $0.01 \%$, Mn $0.33 \%$, P $0.013 \%$, S $0.007 \%$, and Si $0.01 \%$. The second batch's initial density is $7.876 \mathrm{~g} / \mathrm{cm}^{3}$. Its composition is being assayed but is believed to be purer than the first batch. Flyer plates on these projectiles were taken from the same material stock as the target baseplates in all except one experiment. To achieve the highest pressure, $400 \mathrm{GPa}$, a higher density tantalum flyer plate, whose Hugoniot was measured previously, was used.[16-17] Based on the design by Brown and McQueen,[1, 18] our targets are made of three primary components: a baseplate, liquid bromoform $\left(\mathrm{CHBr}_{3}\right)$ analyzer, and an imaging system. The iron baseplates have a diamond-turned flat surface on one side. The other side is made of six or seven parallel flat steps. The step size and thickness have been chosen to minimize the effect of interference from side releases. The step thicknesses are as thin as $1 \mathrm{~mm}$ and as thick as $2.5 \mathrm{~mm}$. Liquid bromoform, which has subnanosecond response time to the traversing shock waves, is used to determine shock wave and catch-up wave arrival times. Analyzers such as bromoform have been shown to be extremely sensitive to small changes in velocity.[19] Lastly, an imaging system, which is comprised of a camera lens, a simple convex lens, and a system of optical fibers, is used to collect light emitted by bromoform. The fiber cores are typically 200 microns in diameter and whose numerical aperture is 0.25 . This fiber-lens-camera system collects light at 14 different points, two or three points on each step. Each of these focussed spots has a diameter of roughly 100 microns and an effective numerical aperture of about 0.125 . Prior to experiments, these light gathering spots are focussed and positioned in an effort to minimize interference from side releases. Catch-up times with side release interference are easily discernible. In such cases, the disturbed data are not used in determination of catch-up distance (fig. 1). Catch-up time here is defined as the time interval between the time the forward moving shock front enters the bromoform to the time rarefaction wave from the flyer catches up to it.

On impact, shock waves travel both forward into the baseplate and backward into the flyer. The time at which the forward moving shock front crosses the iron - bromoform interface is marked by a sharp increase in the intensity of light emitted by bromoform. System response degrades this rise time somewhat, but it is still roughly one or two nanoseconds. This degradation has minimal effect 


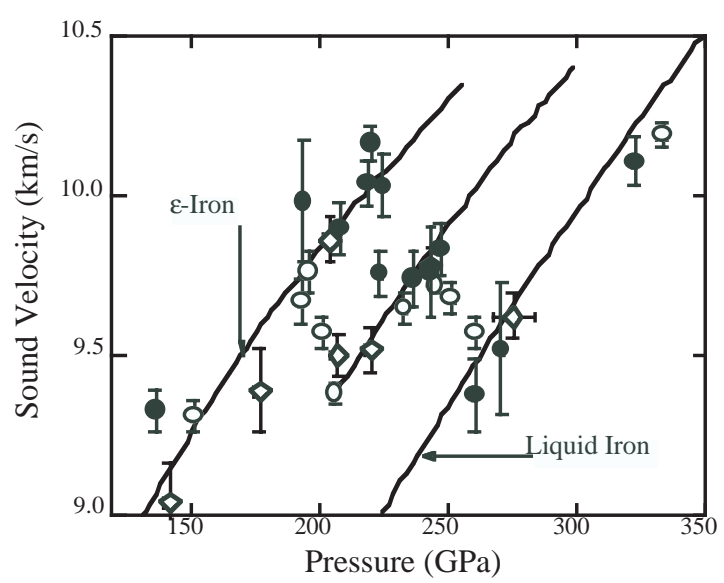

Figure 2. Our sound velocity data, solid circles, show a single phase transition from the solid iron to liquid iron. Open circles and diamonds are Brown and McQueen's sound velocities for gas-gun and explosive driven experiments, respectively.[1] Solid lines are taken from Brown and McQueen.[1] They identified the first line from left as $\varepsilon$-iron, the second line a high pressure solid phase, and the last line liquid iron.

on the catch-up time uncertainty. The light intensity remains relatively constant as the shock front traverses the bromoform, generating a "flat top" profile. The backward moving shock front traverses the entire thickness of the flyer plate. Once reaching the back end of the flyer, a forward

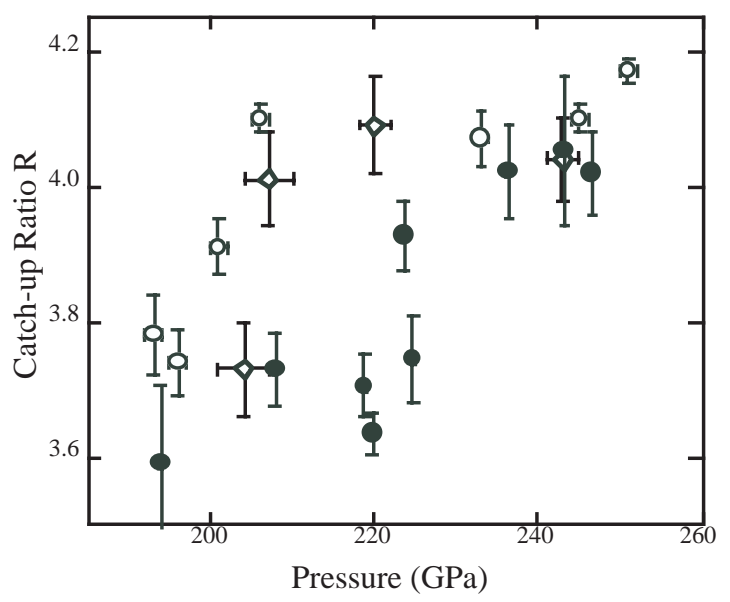

Figure 3. Ratio, R, of the catch-up baseplate thickness to that of the flyer plate thickness. Symbol notations are identical to those in figure 2. Our result for $\mathrm{R}$ is consistent with Brown and McQueen(1) outside of the displayed pressure range. moving release wave, or a rarefaction wave, is generated that moves through both the flyer and the baseplate. Once it catches up to the forward moving shock front, the particle velocity of bromoform and thus the light intensity emitted by bromoform decreases rapidly. The catch-up point is determined from the intersection of the linear fits to the "flat top" and the falling intensity. Catch-up times are functions of the thicknesses of the flyer plate and the baseplate, and the shock pressure. Extrapolation to zero catch-up time, figure 1, yields the minimal baseplate thickness for which release wave catches up to the forward moving shock front before either enters bromoform. We call this minimal baseplate thickness catch-up distance. The ratio, $\mathrm{R}$, of catch-up distance to flyer plate thickness is the "raw" measure of the experiments. Catch-up distance uncertainty was determined from the extrapolation of the $95 \%$ confidence interval lines. Sound velocity, C, can then be calculated using the relation:

$$
C=\frac{\rho_{0}}{\rho} U_{s} \frac{(R+1)}{(R-1)}
$$

where $\rho_{0}$ and $\rho$ are the densities of iron at ambient and high pressure conditions, respectively. $\mathrm{U}_{\mathrm{s}}$ is the shock velocity.

Flyer plate velocity is measured with flash x-ray and has an accuracy of about $0.1 \%$. Shock velocity, $\mathrm{U}_{\mathrm{s}}$, is determined from a fitting to iron Hugoniot data.[20] Its uncertainty is likewise calculated using 95\% confidence interval lines. Initial density, $\rho_{0}$, is determined by water immersion technique and has uncertainty of about $0.1 \%$. High pressure density, $\rho$, is calculated from $\rho_{0}$ and the iron Hugoniot. Sound velocity uncertainties are propagated from these uncertainties.[21]

\section{DISCUSSIONS AND CONCLUSIONS}

Our sound velocity results exhibit a single discontinuity in sound velocity near $250 \mathrm{GPa}$, figure 2 . This result is qualitatively consistent with those of previous shock melting experiments on other metals.[14-15] In particular, Mo, Ta, and Al, exhibit a single drop of roughly ten percent in sound velocity at the solid-liquid phase transition. There is no clear evidence from our work for a solid- 
solid phase transition. Beside the lack of a second discontinuity, our sound velocity data are consistent with Brown and McQueen's, suggesting that the difference noted above is real. Moreover, $\mathrm{R}$ also differs from that of Brown and McQueen, fig. 3, in the pressure range between $200 \mathrm{GPa}$ and $240 \mathrm{GPa}$. This ratio $\mathrm{R}$, a raw data measure, is good comparison tool since it has not been convoluted with iron Hugoniots. $\mathrm{R}$ is consistent with that of Brown and McQueen outside of the abovementioned pressure range.

Our results suggest that there is no triple point in the vicinity of $200 \mathrm{GPa}$. If this is correct, then the iron phase diagram is somewhat simplified. There are, however, disagreements on what the crystalline structure of the solid phase is in this pressuretemperature region. Some believe that it is the $\varepsilon$ hcp phase; others reported a new $\beta$ phase. At ambient pressure and up to $300 \mathrm{GPa}$, iron is known to be in the $\varepsilon$ hcp phase.[7] Whether this $\varepsilon$ hcp phase remains stable up to the melt line [6] or transforms to the $\beta$ phase $[4,8]$ can not be resolved from our data.

\section{ACKNOWLEDGMENTS}

We benefit greatly from discussions with J. M. Brown. Marina Bastea, Ricky Chau, Peter Fiske, David Hare, Michael Hiltl, and William Nellis have provided helpful discussions. We acknowledge Steve Caldwell, Erikk Ojala, Leon Raper, Keith Stickle and many others for their assistance during the experiment. Work performed under the auspices of the U.S. DOE by the LLNL under contract No. W-7405-ENG-48.

\section{REFERENCES}

1. Brown, J. M., and McQueen, R. G., J. Geophys. Res. 91, 7485-7494 (1986); Brown, J. M., and McQueen, R. G., Geophys. Res. Lett. 7, 533-536 (1980).

2. Williams, Q., Knittle, E., and Jeanloz, R., J. Geophys. Res. 96, 2171-2184 (1991); Williams, Q., Jeanloz, R., Bass, J., Svendsen, B., and Ahrens, T. J., Science 236, 181-182 (1987).

3. Boehler, R., Nature 363, 534-536 (1993).

4. Saxena, S. K., Dubrovinsky, L. S., and Häggkvist, P., Cerenius, Y., Shen, G., and Mao, H. K., Science 269, 1703-1704 (1995); Saxena, S. K., Shen, G., and Lazor, P., Science 260, 1312-1314 (1993);
Dubrovinsky, L. S., Saxena, S. K., and Lazor, P., Geophys. Res. Lett. 24, 1835-1838 (1997).

5. Yoo, C. S, Akella, J., Campbell, A. J., Mao, H. K., and Hemley, R. J., Science 270, 1473-1475 (1995).

6. Shen, G., Mao, H. K., and Hemley, R. J., Duffy, T. S., and Rivers, M. L., Geophys. Res. Lett. 25, 373-376 (1998).

7. Mao, H. K., Wu, Y., Chen, L. C., and Shu, J. F., Jephcoat, A. P., J. Geophys. Res. 95, 21,73721,742 (1990).

8. Andrault, D., Fiquet, G., Kunz, M., Visocekas, F., and Häusermann, D., Science 278, 831-834 (1997).

9. Yoo, C. S., Holmes, N. C., and Ross, M., Webb, D. J., and Pike, C., Phys. Rev. Lett. 70, 3931-3934 (1993).

10. Bass, J. D., Ahrens, T. J., Abelson, J. R., and Hua, T., J. Geophys. Res. 95, 21,767-21,776 (1990); Bass, J. D., Svendsen, B., and Ahrens, T. J., "The Temperature of Shock Compressed Iron," in High Pressure Research in Mineral Physics, Geophys. Monogr. Ser., vol. 39, edited by M. N. Manghnani and Y. Syono, AGU, Washington, D.C., 1987, pp. 393-402.

11. Ross, M., Young, D. A., and Grover, R., J. Geophys. Res. 95, 21,713-21,716 (1990).

12. Söderlind, P., and Moriarty, J. A., Wills, J. M., Phys. Rev. B 53, 14,063-14,072 (1996).

13. Chen, G., and Ahrens, T. J., Geophys. Res. Lett. 22, 21-24 (1995).

14. Shaner, J. W., Brown, J., M., and McQueen, R. G., Mat. Res. Soc. Symp. Proc. 22, 137-141 (1984).

15. Hixson, R. S., Boness, D. A., and Shaner, J. W., Moriarty, J. A., Phys. Rev. Lett. 62, 637 (1989).

16. Mitchell, A. C., and Nellis, W. J., J. Appl. Phys. 52, 3363-3374 (1981).

17. Holmes, N. C., Moriarty, J. A., Gathers, G. R., and Nellis, W. J., J. Appl. Phys. 66, 2962-2967 (1989).

18. McQueen, R. G., Hopson, J. W., and Fritz, J. N., Rev. Sci. Instrum. 53, 245-250 (1982).

19. McQueen, R. G., and Isaak, D. G., "Bromoform $\left(\mathrm{CHBr}_{3}\right)$ - A Very High-Pressure Shock-Wave Analyzer," in Shock Compression of Condensed Matter - 1989, edited by S. C. Schmidt, J. N. Johnson, and L. W. Davison, Shock Waves in Condensed Matter - 1989, Amsterdam 1990, pp. 125-128.

20. McQueen, R. G., and Marsh, S. P., J. Appl. Phys. 31, 1253 (1960); Al'tshuler, L. V., Krupnikov, K. K., Ledenev, B. N., Zhuchikhin, V. I., and Brazhnik, M. I., Soviet Phys.-JETP 34, 606 (1958).

21. Bevington, P. R., Data Reduction and Error Analysis for the Physical Sciences, McGraw-Hill, San Francisco, 1969, pp. 56-65. 